\title{
Energy Management Strategy to Coordinate Batteries and Ultracapacitors of a Hybrid Energy Storage System in a Residential Prosumer Installation
}

\author{
M. Ruiz-Cortés, E. Romero-Cadaval, C. Roncero-Clemente, F. Barrero-González, E. González-Romera \\ Power Electrical and Electronic Systems (PE\&ES) \\ University of Extremadura \\ Badajoz, Spain
}

\begin{abstract}
In recent years, power systems have experimented a great development as a consequence of the apparition of the distributed generation. Renewable energy sources, active users and electric vehicles play a fundamental role in power systems, which has supposed a new topic research. In this scenario, the figure of prosumer has gained relevance due to the multiple advantages that they can contribute to improve the behavior of power systems and to achieve energy and cost savings. In particular, special attention is focus on photovoltaic (PV) arrays integrated in residential buildings with energy storage systems (ESSs), such as batteries or ultracapacitors (UCs) or even a combination of both in a hybrid energy storage system (HESS). This paper presents an energy management strategy to exchange energy between the batteries and the UCs that form a HESS installed with a PV array in a prosumer dwell in order to maintain its UC bank available to support the energy requirements during the most time possible.
\end{abstract}

Keywords-prosumer; battery; ultracapacitor; hybrid energy storage system; energy management strategy

\section{INTRODUCTION}

In last years, the proliferation of distributed generation has caused power systems have to face multiple challenges [1] in order to integrate renewable energy sources, electric and hybrid vehicles and active users into the grid. Distributed generation needs to solve several technical issues associated with it, such as electromagnetic interference, harmonic distortion, problems in voltage and frequency regulation or islanding [2]. As a possible solution to mitigate the problems exposed below, a new concept about the role of end users has appeared recently: end users have been called to become prosumers, instead of being considered only as consumers.

A prosumer can be defined as a combination of a producer and a consumer. It means that a prosumer is able both to extract power from the grid (like a conventional consumer) and to deliver power into the grid (like a producer) [3]. At installations of prosumers, loads and energy sources coexist, in a way that the energy sources provide energy to feed their own loads or to inject power to the electric grid according to economic decisions. For this reason, a large number of prosumers can contribute to smooth the energy demand curve, and, therefore, to reduce the required power generation. In addition, prosumers which are equipped with control and communication systems can provide services to the power system, such as the increase of the penetration of intermittent renewable energy sources (like photovoltaic and wind sources) into the grid, the load/generation shifting, ancillary services and grid system applications [3], [4]. Thus, it is possible to decrease both the required peak power generation and the charge on the electric grid, and therefore a reduction of the usage of fossil fuels [5]; moreover, it allows that end users achieve lower electricity bills and to optimize the utilization of renewable energy sources [4].

The renewable energy source which has experimented de greatest development in the last years has been the PV generation [6], especially in residential and commercial installations connected to low voltage distribution networks [2], [7]. The growth of small PV plants has been considerably high in urban areas, where they use to be integrated to the roofs of buildings [8], instead of occupy large land areas, and allow users can benefit from electricity cost savings [2].

In spite of the multiple advantages that PV systems offer, they also present some issues. In residential applications, the peak power consumption is usually produced in the evening; however, the peak power generation is usually produced at noon; hence, a mismatch between peak PV power generation and peak power consumption times occurs [5]. At this disadvantage, we have to add the intermittent and unpredictable character of PV generation as a result of its dependence of the solar irradiance. These problems can be mitigated incorporating an ESS associated to the PV installations, whose main purpose is to store the excess of power produced by the PV system in order to deliver the necessary energy to satisfy the user demand when PV power is insufficient [7]. ESS can be designed using different technologies and even combining up to one of them to compose a hybrid energy storage system (HESS) [9].

This paper focuses on simulating by Simulink/Matlab software the operation of a residential prosumer installation with a PV array and a HESS based on batteries and ultracapacitors, as shown in Fig. 1. A brief explanation about ESS technologies and HESS configurations that can be integrated in PV systems is offered in Section II. In Section III, 
the analyzed case study is described, showing the typical power generation and consumption curves of the prosumer. In addition, in Section IV an energy management system (EMS) is proposed in order to maintain UCs voltage in a desired level within the HESS by means of exchanging energy between the batteries and the UCs. Simulation results obtained for the case study are discussed in Section $\mathrm{V}$ in order to evaluate if the proposed control strategy is valid. Finally, in Section VI, the main conclusions which have been obtained in this work are exposed.

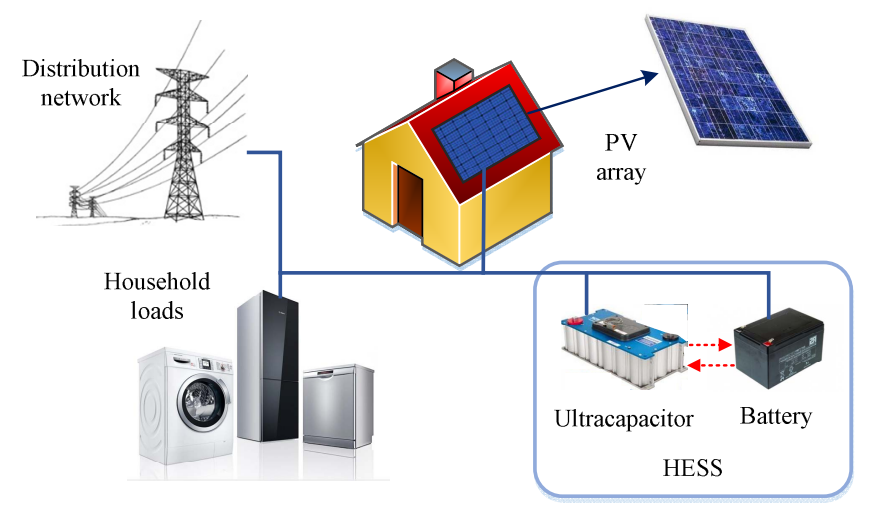

Fig. 1. Case study scenario.

\section{ESSS INTEGRATED IN PV SYSTEMS}

ESSs have become in an interesting topic to move forward in research in recent years. In the case of residential PV systems, ESSs are destined to store the surplus of power from the PV system during noon time and hence reducing the energy loss associated with the excess power from the solar PV array [7] and decreasing the injection in the grid from the PV system [1], due to an uncontrolled power supply to the grid could cause issues. This stored energy could be used later to feed the load when PV supply is not sufficient, serving as support to the grid and reducing the electric consumption of the user. Therefore, ESSs allow the displacement of the energy consumption of customers, in a way that they only inject when the energy is needed most and charge their ESSs when there is an excess of generation or the price of the energy are cheaper than in other periods [1]. Hence, ESSs contribute to smooth the load consumption curve and to improve the energy management [1].

Multiple technologies can be used in a ESS. Some of them are the next [10]: pumped hydroelectric storage (PHS), compressed air energy storage (CAES), batteries, fuel cells, flow batteries, solar fuels, superconducting magnetic energy storage (SMES), flywheels, UCs or thermal energy storage (TES). Each one of them presents different characteristics regarding technical maturity, power and energy density, power rating and discharge time, storage duration, capital cost, cycle efficiency, life time and life cycle, influence on environment and size. Because of this, it is essential to decide what technology is the most suitable for the application in question [11]. For example, PHS is a mature technology with large volume, long storage period, high efficiency and relatively low capital cost per unit of energy [10], but it is unfeasible to integrate a PHS based ESS with a residential PV installation. The most common technologies which have been proposed to be combined with PV systems are batteries, UCs or fuel cells [12].

In the design of a ESS associated to a PV system it is important to take account that PV power is composed by a lowfrequency component and high-frequency oscillations associated to the intermittency of the solar irradiance. Thus, in order to smooth the low-frequency oscillations, a ESS with high energy density is required, while ESS with high power density is also required to provide or absorb the high-power transients [13].

Batteries are the most employed ESS with PV systems, and they are able to store acceptable amounts of energy, although they can not deliver large amount of energy in a very short time [14]. On the other hand, UCs can supply high peaks of energy and can be charged and discharged without missing of efficiency for thousands of cycles, but their storage capacity is low [14]. Both technologies can be combined to add the high energy density of batteries to the high power density of UCs [9], [11], [13], [14]. This combination provides another advantage, because the inclusion of UCs can contribute to improve the batteries lifetime due to they are responsible for provide high power demands [9]. This combination of ESS technologies makes up a hybrid energy storage system (HESS) [9]. Hence, a HESS based on batteries and UCs is characterized by a fast response and a large energy capacity [15].

Different topologies of HESSs exist. In [16] and [17], a review of the most widely used HESS topologies is given, which are classified in passive and active configurations with different possibilities concerning the number of power converters and the position of the used storage devices. However, one of the most used HESS topologies is the parallel configuration of the battery/ultracapacitor HESS with bidirectional converters (multiple converter configuration). The use of bidirectional converters allows managing each ESS independently and even exchanging the energy between the ESSs [9], for example, the batteries can charge and discharge the UCs, which is very useful to guarantee that UCs are available to support batteries at all times. In addition, this topology allows to maintain both the battery and the UC voltage lower than the dc-link voltage, which avoids balancing problems; also, the UC voltage can vary in a wide range, therefore, the capacitor is fully used, but two converters are required [16].

\section{CASE STUDY}

The proposed case study has been represented in Fig. 1. It consists on a residential prosumer installation connected to a low distribution network. It has a small PV array whose peak PV power is equal to $3 \mathrm{kWp}$. This prosumer is able to store energy in a HESS based on the combination of lead-acid batteries and UCs. The HESS has been dimensioned in order to batteries have three days of autonomy [18]. The characteristics of the PV array and the HESS are collected in Table I. The typical diary PV generation and load consumption profiles of the analyzed prosumer are shown in Fig. 2. These curves have 
been obtained through the simulation of provided data using Simulink/Matlab software.

TABLE I. SimUlation PARAMETERS

\begin{tabular}{|l|c|}
\hline \multicolumn{1}{|c|}{ Parameter } & Value \\
\hline Peak PV power & $3 \mathrm{kWp}$ \\
\hline Battery bank capacity & $2000 \mathrm{Ah}$ \\
\hline Ultracapacitor bank capacity & $600 \mathrm{~F}$ \\
\hline HESS devices voltage & $48 \mathrm{~V}$ \\
\hline
\end{tabular}

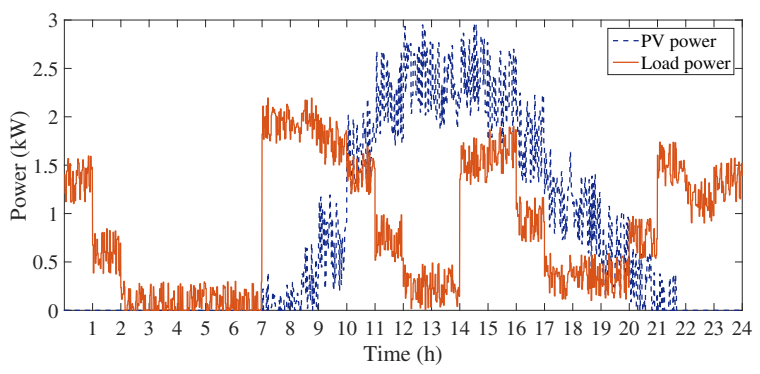

Fig. 2. PV generation and load consumption curves of the prosumer.

\section{Proposed ENERGY MANAGEMENT STRATEGY}

In order to the devices of a HESS could interact properly with the PV system and even between themselves, an EMS is required. As we mentioned in Section II, batteries are suitable to provide the bulk of energy during large intervals of time, but its response is slow, and, because of this, UCs are responsible for supplying the power peak demands and absorbing the PV peak power excess, due to their fast response. For this reason, it is needed to separate the low-frequency component of the power assumed by the HESS, which is destined to the battery, and the high-frequency component, which is took on the UC.

This objective can be reached using a conventional lowpass filter [13], that distribute the power among the storage devices depending on their response times: the low frequency power part is assigned to the long-term storage device (batteries in this case), and the rest is absorbed/supplied by the short-term storage device (UCs in this case) [17]. This power sharing is represented by (1), (2) and (3), where the power that have to be provided by the HESS $\left(P_{\text {refsto }}\right)$ is calculated as the difference between the demanded power $\left(P_{\text {load }}\right)$ and the PV generated power $\left(P_{P V}\right)$, whereas $P_{b a t}$ and $P_{U C}$ are the power assigned to the batteries bank and the UCs bank respectively. Fig. 3 shows the block diagram used in Simulink in order to model the previous equations, and it has been designed using the guidelines of [19].

As it is mentioned in [17], the explained power distribution method is not enough to coordinate the HESS, but it can be used as a first power distribution procedure. Also, an EMS must have into account the state of charge (SOC) of the storage devices that form the ESS or the HESS.

In the case of batteries, their capacity is defined as the quantity of electrical charge in the cell from the fully charged

$$
P_{\text {ref }, \text { sto }}=P_{\text {load }}-P_{P V}
$$

$$
P_{b a t}=\operatorname{LPF}\left(P_{r e f, s t o}\right)
$$

$$
P_{U C}=P_{r e f, s t o}-P_{b a t}
$$

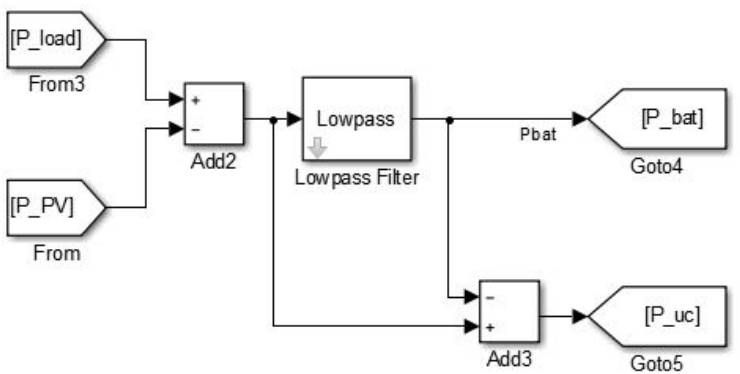

Fig. 3. Simulink diagram used to calculate $P_{b a t}$ and $P_{U C}$.

state to the discharged state [20]. Thus, the SOC of a battery $\left(S O C_{b a t}\right)$ means the ratio between the remaining capacity $(Q)$ and the full charge or nominal charge $\left(Q_{n o m}\right)$, as it is shown in (4). Hence, a SOC equal to $100 \%$ implies that the battery is fully charged, whereas a SOC equal to $0 \%$ indicates that the battery is fully discharged [20]. However, the SOC of a battery is usually calculated following (5), where $S O C_{b a t, 0}$ and $i$ are the initial SOC and the output current of the battery respectively, and it is expressed in Ampere-hour (Ah).

$$
\begin{gathered}
S O C_{b a t}=\frac{Q}{Q_{n o m}} \\
S O C_{b a t}=S O C_{b a t, 0}-\int \frac{i d t}{Q}
\end{gathered}
$$

Moreover, the lifespan of a battery can be damaged if it works out of a certain working range [21]. Because of this, a limitation of the SOC of the batteries has been considered in this paper. In this way, batteries are able to work only within a range whose upper limit has been established in a value of $100 \%$ and the lower limit is equal to $20 \%$, according to leadacid batteries characteristics [18]. Thus, it is possible to avoid the over-charging and the over-discharging of the batteries.

On the other hand, the stored energy in an UC $\left(E_{U C}\right)$ can be calculated using (6), where $V$ is the voltage of the UC in a certain instant and $C$ is the UC capacity [22]. As we can see in (6), an UC stores energy proportionally to the square of its voltage [23]. UCs are usually interfaced with the rest of the installation by a power converter, which needs a minimum operating voltage and, therefore, a minimum energy [24]. Thus, the SOC of an UC $\left(S O C_{U C}\right)$ can be expressed as it is shown in (7), where $E$ is the stored energy in the UC at a certain moment, whereas $E_{\max }$ and $E_{\min }$ are the maximum and the 
minimum energy that the UC is able to store. In this way, $S O C_{U C}$ is the ratio between the available energy in a determined instant and the total energy that the UC is able to provide.

$$
\begin{gathered}
E_{U C}=\frac{1}{2} \cdot C \cdot V^{2} \\
S O C_{U C}=\frac{E-E_{\text {min }}}{E_{\max }-E_{\min }}
\end{gathered}
$$

Using (7), when the UC voltage reaches the $50 \%$ of its nominal value, $S O C_{U C}$ is equal to $0 \%$. It means that an $\mathrm{UC}$ is considered as fully discharged when its voltage is the half of its nominal value $\left(V_{\text {nom }}\right)$, in order to maintain a minimum energy equal to $25 \%$ of the total energy that the UC could store (8) and ensure the minimum operating voltage required by the power converter.

$$
E_{\text {min }}=\frac{1}{2} \cdot C \cdot\left(\frac{V_{\text {nom }}}{2}\right)^{2}=\frac{1}{4} \cdot\left[\frac{1}{2} \cdot C \cdot\left(V_{\text {nom }}\right)^{2}\right]=0.25 E_{\max }
$$

With the aim of guaranteeing that the UC bank is always available to provide or absorb the required power, it is necessary to maintain $S O C_{U C}$ in a certain level [13]. In this paper, we have established the desired $S O C_{U C}$ equal to $50 \%$. As a consequence, we need to calculate the corresponding reference voltage $\left(V_{r e f}\right)$ to a $S O C_{U C}$ equal to $50 \%$. This can be achieved using (9), which relates $S O C_{U C}$ with $V$ and $V_{n o m}$ and is the result of combining (6), (7) and (8). Thus, in the analyzed case study, $V_{\text {ref }}$ must be around 37.95 V. Fig. 4 depicts the relation between $S O C_{U C}$ and $V$ in a general case.

$$
\operatorname{SOC}_{U C}=\frac{1}{3} \cdot\left[4 \cdot\left(\frac{V}{V_{\text {nom }}}\right)^{2}-1\right]
$$

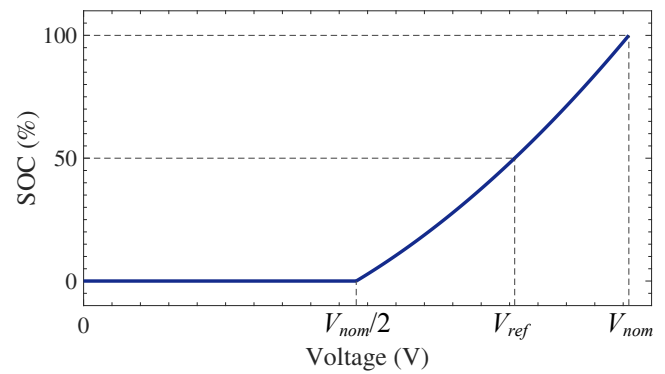

Fig. 4. Evolution of $S O C_{U C}$ with $V$.

In order to achieve this purpose, the HESS batteries can cooperate with the UC bank thanks to a coordination realized by the EMS [9]. In this way, when the UC voltage falls below $V_{\text {ref, }}$, the EMS generates a current reference through a PI controller to charge the UC from the battery until the UC reaches $V_{\text {ref }}$ again and vice versa. With this control action, the $\mathrm{UC}$ remains at every moment able to provide energy (positive or negative), avoiding that it suffers high charge fluctuations.

Fig. 5 shows the model built in Simulink in order to simulate the HESS and its energy management to exchange energy between batteries and UCs. As we can see in this figure, we have used the battery and UC models that Simulink

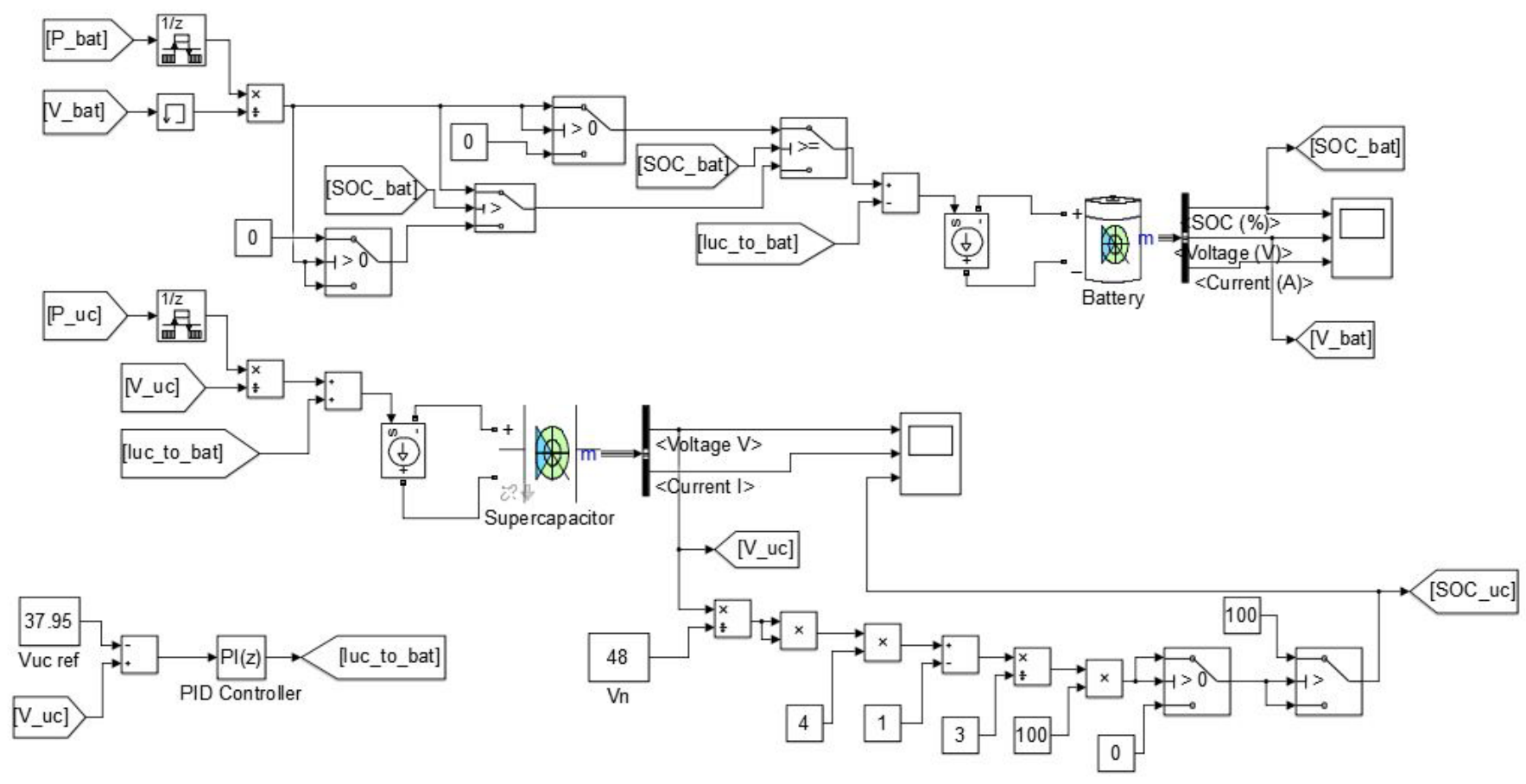

Fig. 5. Simulink model used to simulate the battery and UC banks work with the proposed control. 
provides in SimPowerSystems Blockset. Both blocks receive their corresponding reference current signals through controlled current sources. The PI controller has been tuned using the PID Tuner tool, using $K_{P}=10$ and $K_{I}=200$.

\section{Simulation Results}

The proposed energy management strategy has been tested by simulation in the HESS of the studied prosumer to coordinate the energy flow between the battery and the UC systems that compose the HESS, with $S O C_{b a t}=65 \%$ and $V=40$ $\mathrm{V}$ as initial values. As we can see in Fig. 6, the control strategy accomplishes the requirement of avoiding UCs suffer saturation when their SOC reaches $100 \%$ and a fully discharge. Instead of this, the voltage of the UC bank is maintained in the calculated value (Fig. 6(a)), and, as a consequence, $S O C_{U C}$ is approximately equal to $50 \%$ along the simulation time (Fig. 6(b)). This has been achieved through the exchange of energy between the battery and the UC banks. Thus, the SOC of the battery has been affected in the way shown in Fig. 6(c), which compares the SOC of the battery when the proposed EMS is used with the case in that it is not applied. In this figure, it can be observed how the battery provides and absorbs

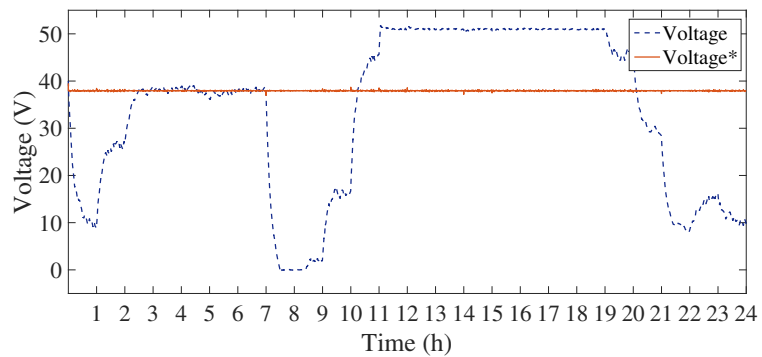

(a)

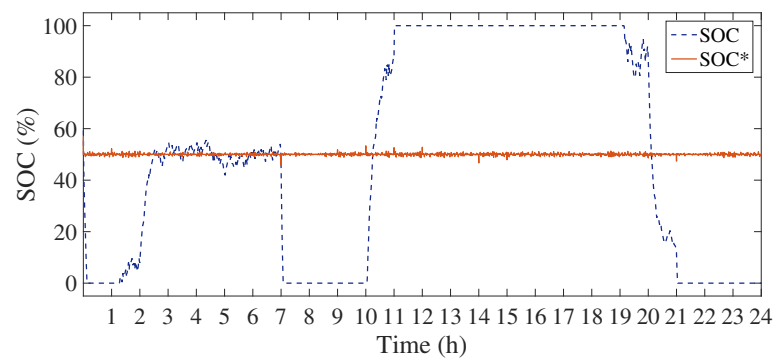

(b)

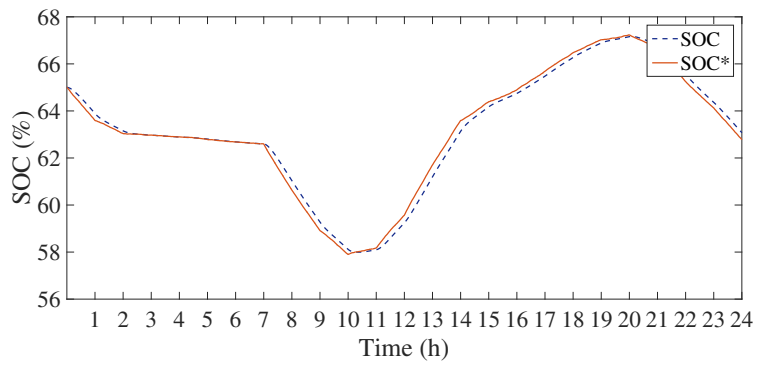

(c)

Fig. 6. Comparison of the evolution of the voltage (a) and the SOC (b) of the UC system and the SOC of the batteries bank (c) along a day with the proposed control action (marked with *) and without it. energy to the UC when it is necessary in order to $S O C_{U C}$ remains in the desired value. However, the difference between both SOC curves is small.

In the other hand, Fig. 7 shows the current that the battery and the UC supply respectively during the period contained between 7:00 a.m. and 4:00 p.m. As it can be observed, the batteries system delivers the low-frequency component of the required current, whereas the UCs system provides the required high-frequency component of the current to operate properly with the PV system. In order to understand the figure, it is important to take into account that we have consider positive currents imply discharge in the ESSs and negative currents mean charge.

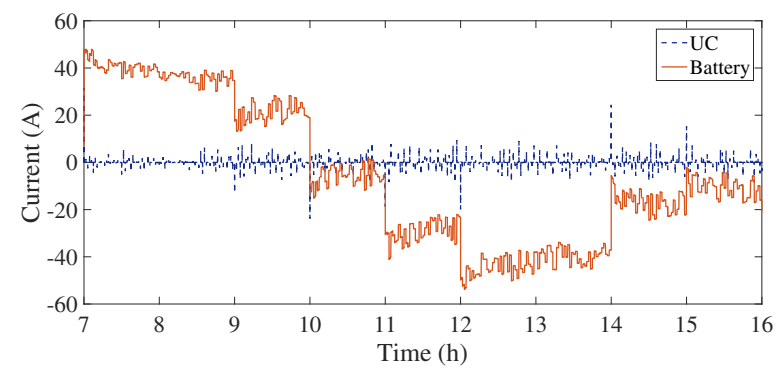

Fig. 7. Comparison of the currents provided by the battery and the UC systems since 7:00 a.m. to 4:00 p.m.

\section{CONCLUSIONS}

This paper exposes the relevance that prosumers have reached as a result of the new scenario that the development of distributed generation has caused in recent years. Besides, a brief discussion about ESSs is given. Namely, the case of a prosumer dwell with a small PV array combined with a HESS based on lead-acid batteries and UCs has been simulated. Moreover, a comprehensive control strategy has been proposed in order to optimize the energy management and it has been validated by simulation.

The implemented EMS allows maintaining the SOC of the UC bank in the half of their maximum value, which is useful to UCs remain available at all times and even to take advantage of the surplus of the energy stored in UCs to charge batteries.

As further works, it would be interesting to continue analyzing the proposed EMS with different PV conditions and load characteristics in order to evaluate its operation in other possible cases. In addition, this work could be complemented with an economical study which considers the variable energy prices and allows to determine the economic impact that a HESS and a EMS can cause in a residential installation.

\section{ACKNOWLEDGMENT}

This research work has been partially supported by the project (TEC2016-77632-C3-1-R) from "Ministerio de Economía y Competitividad (Gobierno de España)" and by "Junta de Extremadura" with funds for research groups (GR15177). 


\section{REFERENCES}

[1] S. M. Souza, M. Gil, J. Sumaili, A. G. Madureira and J. A. P. Lopes, "Operation scheduling of prosumer with renewable energy sources and storage devices," 2016 13th International Conference on the European Energy Market (EEM), Porto, 2016, pp. 1-5.

[2] R. Araneo and M. C. Falvo, "Simulation of a ESS in a prosumer powerplant with a PV system and an EV charging station," 2016 IEEE 16th International Conference on Environment and Electrical Engineering (EEEIC), Florence, 2016, pp. 1-5.

[3] M. C. Falvo, U. Grasselli, M. Manganelli and A. Modesto, "Small scale ESS for LV prosumers: An economic feasibility and sensitivity analysis," 2015 IEEE 15th International Conference on Environment and Electrical Engineering (EEEIC), Rome, 2015, pp. 950-955.

[4] G. Graditi, M.G. Ippolito, R. Rizzo, E. Telaretti, and G. Zizzo, "Technical-Economical Evaluations for Distributed Storage Applications: An Italian Case Study for a Medium-Scale Public Facility". Paper presented at 3rd Renewable Power Generation Conference - RPG 2014, Napoli.

[5] Y. Wang, X. Lin and M. Pedram, "Adaptive Control for Energy Storage Systems in Households With Photovoltaic Modules," in IEEE Transactions on Smart Grid, vol. 5, no. 2, pp. 992-1001, March 2014.

[6] E. Romero-Cadaval, G. Spagnuolo, L. G. Franquelo, C. A. Ramos-Paja, T. Suntio and W. M. Xiao, "Grid-Connected Photovoltaic Generation Plants: Components and Operation," in IEEE Industrial Electronics Magazine, vol. 7, no. 3, pp. 6-20, Sept. 2013.

[7] M. J. E. Alam, K. M. Muttaqi and D. Sutanto, "Mitigation of Rooftop Solar PV Impacts and Evening Peak Support by Managing Available Capacity of Distributed Energy Storage Systems," in IEEE Transactions on Power Systems, vol. 28, no. 4, pp. 3874-3884, Nov. 2013.

[8] M. Sechilariu, B. Wang and F. Locment, "Building Integrated Photovoltaic System With Energy Storage and Smart Grid Communication," in IEEE Transactions on Industrial Electronics, vol. 60, no. 4, pp. 1607-1618, April 2013.

[9] M. Momayyezan, D. B. W. Abeywardana, B. Hredzak and V. G. Agelidis, "Integrated Reconfigurable Configuration for Battery/Ultracapacitor Hybrid Energy Storage Systems," in IEEE Transactions on Energy Conversion, vol. 31, no. 4, pp. 1583-1590, Dec. 2016.

[10] H. Chen, T. N. Cong, W. Yang, C. Tan b, Y. Li, Y. Ding, "Progress in electrical energy storage system: A critical review," Progress in Natural Science, vol. 19, 2009, pp. 291-312.

[11] E. Romero-Cadaval, B. Francois, M. Malinowski and Q. C. Zhong, "Grid-Connected Photovoltaic Plants: An Alternative Energy Source, Replacing Conventional Sources," in IEEE Industrial Electronics Magazine, vol. 9, no. 1, pp. 18-32, March 2015.

[12] H. Beltran, E. Bilbao, E. Belenguer, I. Etxeberria-Otadui and P. Rodriguez, "Evaluation of Storage Energy Requirements for Constant Production in PV Power Plants," in IEEE Transactions on Industrial Electronics, vol. 60, no. 3, pp. 1225-1234, March 2013.

[13] H. Zhou, T. Bhattacharya, D. Tran, T. S. T. Siew and A. M. Khambadkone, "Composite Energy Storage System Involving Battery and Ultracapacitor With Dynamic Energy Management in Microgrid Applications," in IEEE Transactions on Power Electronics, vol. 26, no. 3, pp. 923-930, March 2011.

[14] H. F. Gharibeh, A. S. Yazdankhah and M. R. Azizian, "Improved energy management for a power-split multi-source fuel cell vehicle based on optimal source sizing and regenerative braking," 2016 IEEE 16th International Conference on Environment and Electrical Engineering (EEEIC), Florence, 2016, pp. 1-6.

[15] C. Abbey, K. Strunz and G. Joos, "A Knowledge-Based Approach for Control of Two-Level Energy Storage for Wind Energy Systems," in IEEE Transactions on Energy Conversion, vol. 24, no. 2, pp. 539-547, June 2009.

[16] J. Cao and A. Emadi, "A New Battery/UltraCapacitor Hybrid Energy Storage System for Electric, Hybrid, and Plug-In Hybrid Electric Vehicles," in IEEE Transactions on Power Electronics, vol. 27, no. 1, pp. 122-132, Jan. 2012.

[17] A. Etxeberria, I. Vechiu, H. Camblong, J. M. Vinassa and H. Camblong, "Hybrid Energy Storage Systems for renewable Energy Sources Integration in microgrids: A review," 2010 Conference Proceedings IPEC, Singapore, 2010, pp. 532-537.

[18] M. E. Glavin, P. K. W. Chan, S. Armstrong and W. G. Hurley, "A standalone photovoltaic supercapacitor battery hybrid energy storage system," 2008 13th International Power Electronics and Motion Control Conference, Poznan, 2008, pp. 1688-1695.

[19] C. R. Akli, X. Roboam, B. Sareni and A. Jeunesse, "Energy management and sizing of a hybrid locomotive," 2007 European Conference on Power Electronics and Applications, Aalborg, 2007, pp. $1-10$.

[20] O. Palizban and K. Kauhaniemi, "Power sharing for distributed energy storage systems in AC microgrid: Based on state-of-charge," 2015 IEEE PES Asia-Pacific Power and Energy Engineering Conference (APPEEC), Brisbane, QLD, 2015, pp. 1-5.

[21] J. Zou, C. Peng, J. Shi, X. Xin and Z. Zhang, "State-of-charge optimising control approach of battery energy storage system for wind farm," in IET Renewable Power Generation, vol. 9, no. 6, pp. 647-652, 82015.

[22] M. A. Guerrero-Martínez, E. Romero-Cadaval, F. Barrero-González, M. I. Milanés-Montero and E. González-Romera, "Overview of medium scale energy storage systems," 2009 Compatibility and Power Electronics, Badajoz, 2009, pp. 93-100.

[23] H. Yin, W. Zhou, M. Li, C. Ma and C. Zhao, "An Adaptive Fuzzy Logic-Based Energy Management Strategy on Battery/Ultracapacitor Hybrid Electric Vehicles," in IEEE Transactions on Transportation Electrification, vol. 2, no. 3, pp. 300-311, Sept. 2016.

[24] M. A. Guerrero-Martínez, E. Romero-Cadaval, M. I. Milanés-Montero, V. M. Miñambres-Marcos and F. Barrero-González, "Aplicación de Sistemas de Almacenamiento de Energía con Supercondensadores en Plantas de Generación Fotovoltaica," Seminario Anual de Automática, Electrónica Industrial e Instrumentación 2009. Actas de Congreso, Leganés, 1-3 July 2009. 